DOI 10.37882/2223-2982.2021.04-2.16

\title{
К ВОПРОСУ ОБ ОПРЕДЕЛЕНИИ ОСОБЫХ ОБРАЗОВАТЕЛЬНЫХ ПОТРЕБНОСТЕЙ ОБУЧАЮЩИХСЯ С ОГРАНИЧЕННЫМИ ВОЗМОЖНОСТЯМИ ЗДОРОВЬЯ
}

\section{ON THE ISSUE OF DETERMINING THE SPECIAL EDUCATIONAL NEEDS OF STUDENTS WITH DISABILITIES}

\section{N. Kozhanova}

Summary: The purpose of this article is to clarify and define the content of the concept of "special educational needs" and how to identify them. Based on the analysis of psychological and defectological concepts, the content of the concept of "special educational needs" is determined and the developed indicative basis for the teacher's identification of a list of such needs available to a student with disabilities for the implementation of his education is presented. The requirements for the content of the list of educational needs of students with disabilities are scientifically justified and presented, a method of professional action is developed to identify the special educational needs of the student, which must be provided for the organization of the pedagogical process in inclusive education.

Keywords: special educational needs, students with disabilities, inclusive education, special education, inclusion.

\section{Введение}

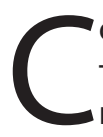
окращение количества специальных образовательных организаций, оказывающих коррекционные услуги в субъектах Российской Федерации, автоматически привело к тому, что в различных регионах страны коррекционные школы стали закрываться, а учащимся с отклонениями в развитии рекомендовано обучаться в общеобразовательных организациях.

Ни в коем случае не обесценивая того факта, что инклюзия действительно является одним из важнейших направлений развития системы Российского образования, направленного на поддержку и поощрение разнообразия среди всех обучающихся (Федеральный закон от 29.12.2012 N 273-Ф3 (ред. от 02.12.2019) "Об образовании в Российской Федерации" (с изм. и доп., вступ. в силу с 13.12.2019) Ст. 2 п.27.), мы должны отметить тот факт, что часть обучающихся с ограниченными возможностями здоровья (далее ОВ3) обучается в общеобразовательных организациях без своевременного диагностирования, а, следовательно, без учета их Особых образовательных потребностей и создания адекватных условий, их обеспечения.

\author{
Кожанова Наталья Сергеевна \\ к.n.н., доцент, БУ ВО «Сургутский государственный \\ педагогический университет» \\ nskozhanova@rambler.ru
}

Аннотация: Целью данной статьи является уточнение и определение содержания понятия «особые образовательные потребности» и способа их выявления. На основе анализа психологических и дефектологических концепций определено содержание понятия «особые образовательные потребности» и представлена разработанная ориентировочная основа действия выявления педагогом перечня таких потребностей, имеющихся у обучающегося с ограниченными возможностями здоровья для реализации его образования. Научно обоснованы и представлены требования к содержанию перечня образовательных потребностей обучающихся с ограниченными возможностями здоровья, разработан способ профессионального действия выявления особых образовательных потребностей обучающегося, которые необходимо обеспечить при организации педагогического процесса в инклюзивном образовании.

Ключевые слова: особые образовательные потребности, обучающиеся с ограниченными возможностями здоровья, инклюзивное образование, специальное образование, инклюзия.

Термин «особые образовательные потребности» нормативно закреплен в Российской Федерации и стал общепризнанным в научно-педагогических исследованиях $[2$, с.1].

В этой связи нормативные документы четко предписывают учитывать особые образовательные потребности обучающегося, которые лежат в основе определения специальных условий организации образования лиц с OB3 $[6,7,8,9]$. Научное сообщество в рамках концепции специального образования разработанной детей с ОВ3 ставит задачу разработки понятия «особые образовательные потребности» применительно к каждой нозологической группе, каждому типологическому варианту и возрастному этапу развития [5, с.3].

Данная статья имеет цель определить содержание понятия «особые образовательные потребности» и представить разработанную ориентировочную основу действия выявления педагогом списка таких потребностей у обучающегося с ограниченными возможностями здоровья для реализации его образования.

Сегодня в образовании использование термина 
«особые образовательные потребности» является общепринятым и это смещает акцент в характеристике обучающихся с недостатков, нарушений, отклонений от нормы на фиксацию их потребностей в особых ресурсах и условиях, указывает на необходимость выявления и реализации этих потребностей.

Прежде чем начать выяснять какие образовательные потребности есть у обучающихся той или иной нозологической группы, мы проанализировали научные концепции Е.Л. Гончаровой и О.И. Кукушкиной, В.З. Денискиной, Т.Г. Богдановой, учений Л.С Выготского, В.А. Аверина, А.Н. Леонтьева и др. и разработали содержание понятия «особые образовательные потребности».

Результат анализа представлен в табл. 1.

Таким образом, под «особыми образовательными по- требностями» (ООП) мы будем понимать опосредованные образовательными отношениями особые (атипичные, специфические) психические состояния индивида, при которых, в процессе освоения образовательной программы он воспринимает недостаток (или избыток) в объектах, необходимых для его функционирования и развития при овладении знаниями, умениями, навыками и компетенциями.

Профессиональный стандарт "Педагог (педагогическая деятельность в сфере дошкольного, начального общего, основного общего, среднего общего образования) (воспитатель, учитель)", утвержденный Приказом Министерства труда и социальной защиты РФ от 18 октября 2013 г. N 544н, указывает на трудовые функции, по «Освоению и применению психолого-педагогических технологий (в том числе инклюзивных), необходимых для

Содержание понятия «особые образовательные потребности»

Таблица 1.

\begin{tabular}{|c|c|}
\hline Какой объект необходимо характеризовать? & особые образовательные потребности \\
\hline В какую большую систему входит объект? & «нужды»-«потребности» - «образовательные потребности» \\
\hline $\begin{array}{l}\text { Каково назначение (функции) данного объ- } \\
\text { екта в этой системе? }\end{array}$ & $\begin{array}{l}\text { Определяются психическими состояниями индивида (обучающегося с ОВЗ) когда он воспринимает } \\
\text { недостаток (или избыток) чего-либо, являющиеся основанием для выделения объектов, необходимых } \\
\text { для его функционирования и развития при овладении знаниями, умениями, навыками и компетенциями } \\
\text { (ФГОС, программы, кадры, мат.-технические усл., в том числе образовательные ресурсы, социальные). }\end{array}$ \\
\hline $\begin{array}{l}\text { Какими свойствами должен обладать } \\
\text { объект действительности для выполнения } \\
\text { своего назначения в этой системе? }\end{array}$ & $\begin{array}{l}\text { Динамичность, т.е. объект не является неизменным, единым и постоянным. } \\
\text { Ситуативность - возникают в процессе освоения содержания образования как особые психические состоя- } \\
\text { ния обучающегося, когда он воспринимает недостаток в необходимых ему объектах } \\
\text { Информативность - должен обуславливать изменения в содержании образования и построение образова- } \\
\text { тельной среды для успешного развития и функционирования обучающегося. }\end{array}$ \\
\hline Каковы признаки (свойства) объекта? & $\begin{array}{l}\text { 1. Учитывают закономерности развития психики общие для нормы и не нормы. } \\
\text { 2. Учитывают специфические закономерности развития лиц с ОВ3. } \\
\text { 3. Учитывают специфические (свойственные отдельной категории, нозологии нарушения) закономерности } \\
\text { развития обучающегося. } \\
\text { 4. Учитывают индивидуальные параметры дизонтогенеза (причину, время возникновения нарушения, } \\
\text { локализацию, структуру дефекта). } \\
\text { 5. Определяют разнообразие и требования к объектам, удовлетворяющим индивида в его функциониро- } \\
\text { вании и развитии в зависимости от текущего состояния его функционирования и развития (физические, } \\
\text { когнитивные, эмоциональные, личностные характеристики) и индивидуальных возможностей адаптации } \\
\text { индивида. } \\
\text { 6. Определяют условия и ресурсы образования. } \\
\text { 7. Обеспечивают требования к образовательной, среде, которую необходимо обеспечить при обучении той } \\
\text { или иной категории детей с отклонениями в развитии. }\end{array}$ \\
\hline Каковы назначения каждого элемента? & $\begin{array}{l}\text { Определять условия и механизмы развития обучающегося. } \\
\text { Определять условия и механизмы компенсации дефекта. } \\
\text { Определять механизмы компенсации дефекта отдельной нозологической группы с учетом их потенциала. } \\
\text { Определяют, условия и механизмы индивидуального развития и компенсации дефекта. } \\
\text { Определяют механизмы использования потенциала образовательной среды. }\end{array}$ \\
\hline Какова исходная форма объекта? & Перечень образовательных потребностей всех лиц с ОВЗ вне зависимости от нозологии. \\
\hline Какова развитая форма объекта? & $\begin{array}{l}\text { Перечень научно обоснованных особых образовательных потребностей каждого индивида (обучающего- } \\
\text { ся) с учетом индивидуального характера структуры дефекта, обеспечивающие возможность индивидуали- } \\
\text { зации образования обеспечивающие возможность индивидуализации образования. }\end{array}$ \\
\hline
\end{tabular}


адресной работы с различными контингентами учащихся: одаренные дети, социально уязвимые дети, дети, попавшие в трудные жизненные ситуации, дети-мигранты, дети-сироты, дети с особыми образовательными потребностями...», «выявление в ходе наблюдения поведенческих и личностных проблем обучающихся, связанных с особенностями их развития» $[9$, с.10] и «организацию образовательного процесса на основе непосредственного общения с каждым ребенком с учетом его особых образовательных потребностей» [9, с.12]. В этой связи, следует вывод, что педагог в своей профессиональной деятельности ежедневно при осуществлении планирования и проектирования программ, конспектов уроков, воспитательных мероприятий для обучающихся с ОВ3, сталкивается с необходимостью выявления особых образовательных потребностей обучающихся. Возникают вопросы: во-первых, владеют ли педагоги способом решения профессиональных задач такого типа; во-вторых, как педагог может понять и быть уверенным, что перечень образовательных потребностей, которые он определил или ему представили, достаточный и правильный, что учет именно этих образовательных потребностей обеспечит успешную деятельность по освоению содержания образования конкретному обучающемуся с ограниченными возможностями.

Проводимые срезы и анкетирование педагогов, работающих или планирующих работать с детьми с ОВ3 и обучающихся на курсах повышения квалификации и профессиональной переподготовки в количестве 120 человек, показали, что все они нуждаются в алгоритме выявления правильного достаточного перечня потребностей обучающегося особых образовательных потребностей обучающегося с ограниченными возможностями здоровья, и в овладении способом решения профессиональных задач такого типа.

Так, нами была разработана ориентировочная основа действия выявления педагогом особых образовательных потребностей обучающегося с ограниченными возможностями здоровья, которую затем предложили для освоения педагогам, обучающимся по программам повышения квалификации и профессиональной переподготовки и которую, в обязательном порядке, осваивают студенты - будущие педагоги.

Исходя из технологии деятельностного подхода, к результату любого профессионального действия предъявляются научно обоснованные требования. Так, на основе анализа научных концепций, нами были сформулированы требования, выступающие впоследствии критериями для оценки результата действия выявления особых образовательных потребностей обучающегося с ограниченными возможностями здоровья.

Критерий 1. Актуальность
Первое требование к выделяемым потребностям это их актуальность для каждого конкретного субъекта в определенный момент времени, в определенной деятельности и т.д.

Е.Л. Гончарова и О.И. Кукушкина указывают, что особые образовательные потребности не постоянны, они могут возникать по совершенно разным причинам, меняться со временем, и, главное, не обязательно быть связанными только со здоровьем обучающегося. Исследователи отмечают, что особые образовательные потребности детей с ОВ3 могут быть обусловлены как первичным и вторичными нарушениями, так и социокультурными факторами [2, с.1].

Т.Г. Богданова так же утверждает, что особые образовательные потребности - не являются едиными и постоянными, - проявляются в разной степени при каждом типе нарушения - разной степени его выраженности, может зависеть от содержания, подлежащего освоению, формы организации урока и других составляющих образовательного мероприятия [1, с.29].

\section{Критерий 2. Достоверность}

Учитывая то, что под потребностью мы понимаем прежде всего психическое состояние, необходимо описать психическое состояние, при котором ребенок испытывает необходимость в том, чтобы «в содержание обучения были введены специальные разделы, условия и ресурсы, направленные на решение задач развития ребенка, отсутствующие в содержании образования нормально развивающегося сверстника». Таким образом, об учете образовательных потребностей можно говорить только после всестороннего изучения каждого ребенка и учет его потребностей в конкретном содержании коррекционно-образовательной работы в каждом образовательном мероприятии, исходя из его особенностей и возрастных потребностей, которые обучающийся не может удовлетворить в силу наличия у него первичного и вторичных нарушений.

Данное требование определяется: 1) точностью и комплексностью диагностики, проводимой с применением наблюдения и стандартизированных диагностических методов; 2) научной обоснованностью диагностических выводов, результатов анализа данных и выделенных потребностей (обоснованных психофизиологической, психологической педагогической и др. науками).

\section{Критерий 3. Субъективный характер потребности}

Данное требование предполагает, что в перечень образовательных потребностей обучающегося нельзя не включать то, что не является потребностями ребенка, а 
больше относятся к потребностям взрослых, учителей, директора школы, т.е., иными словами, нужно актуализировать потенциальную субъективную потребность. Например, если с позиции наших рассуждений рассмотреть следующие особые образовательные потребности, общие для различных категорий детей, можно понять, что это не субъективные потребности обучающегося.

Специалистами выделяются особые образовательные потребности, которые являются общими для детей, несмотря на разницу в их проблемах. К ним можно отнести потребности такого рода:

1. обучение детей с особыми образовательными потребностями должно начинаться сразу же, как только были выявлены нарушения в нормальном развитии. Это позволит не потерять время и достигнуть максимального результата;

2. использование специфических средств для осуществления обучения;

3. в учебную программу должны быть введены специальные разделы, не присутствующие в стандартной школьной программе;

4. дифференциация и индивидуализация обучения;

5. возможность максимально расширить процесс образования за пределы учреждения. Продление процесса учебы после окончания школы. Предоставление возможности молодым людям поступить в университет;

6. участие квалифицированных специалистов (врачей, психологов и др.) в обучении ребенка с проблемами, вовлечение родителей в образовательный процесс.

Учитывая то, что потребность - это психическое состояние, становится не понятным, как описать психическое состояние, при котором ребенок (или даже взрослый человек с ОВ3) испытывает необходимость в том, чтобы «в содержание обучения были введены специальные разделы, направленные на решение задач развития ребенка, по понятным причинам отсутствующие в содержании образования нормально развивающегося сверстника». Если же вчитаться в предлагаемую формулировку, то обнаруживается, что это не «потребности обучающегося», а «потребности педагога». Здесь упомянуты скорее задачи работы педагога (учителя-дефектолога) в специальной (коррекционной) школе. Возникает вопрос: где же «учет особенностей и образовательных потребностей конкретного обучающегося». Об учете образовательных потребностей можно говорить только после всестороннего изучения каждого ребенка и учет его потребностей в конкретном содержании коррекционной работы исходя из его особенностей.

Потребности должны быть обусловлены субъективными возможностями или недостатками обучающего- ся, определять содержание образования и сохранение субъективной активности при освоении определенного содержания. Так, например, в ПАООП выделяется потребность в ранней диагностике и коррекции нарушений. Однако, знание этой потребности не поможет учителю организовать и реализовать урок, эта потребность не самого обучающегося, а его родителей, педагогов. Или потребность в компетентных кадрах, это потребность администрации школы, но не обучающегося. Таким образом, потребность должна быть субъективной, возникающей у ребенка с ОВЗ в освоении конкретного содержания образования.

Данное требование возникает из учения о потребностях. Так, Е.П. Ильин, А.Н. Леонтьев, Б.С. Братусь и др. отмечают важную особенность потребностей как их назначение побуждать психическую активность индивида, постановку цели активности и задач для получения результата деятельности. Потребность личности определяется как «переживаемое человеком состояние внутреннего напряжения, возникающее вследствие отражения в сознании нужды и побуждающее психическую активность, связанную с целеполаганием» [3, с.76]. Речь идет именно о психической активности, которая связывается в дальнейшем с постановкой цели практической деятельности индивида, а, следовательно, определяет его субъектность.

В контексте размышлений о субъективном характере особых образовательных потребностей мы учли и научный факт, содержащийся в учениях о закономерностях развития Л.С. Выготского, который указывает, что дети с ОВ3 развиваются по тем же закономерностям, что и в норме, следовательно, им свойственны та же совокупности базовых субъективных психологических потребностей (формулируем по Э. Эриксону): потребность в ведущей деятельности, потребность в физиологическом комфорте, потребность в действии, в общении, потребность в признании, в самореализации, в принадлежности к обществу и сопричастности к процессу, общению, взаимодействию, деятельности, потребность в эмоциональном комфорте, потребность нравиться окружающим, потребность в отстаивании своего индивидуального, своего авторитета и достоинства (потребность в достойной самооценке), потребность в любви и поддержке т.д. [11].

Безусловно, нарушение и фрустрация этих потребностей вследствие наличия первичных и вторичных нарушений (исходя из структуры дефекта) приводит к нерешенности возрастных задач развития и, как следствие, возникновению нарушений в поведении и деятельности. Снижается активность и субъектная позиция обучающегося в деятельности.

То есть, назревает вывод, что у обучающегося могут 
возникнуть образовательные потребности (типичные или особые) только в самом образовательном процессе по освоению содержания образовательного мероприятия, образовательной программы соответствующего типа.

Пример 1. Для формирования определенных представлений по предмету «История», необходима наглядность (карта, схема, др.), незрячий обучающийся не имеет возможности чтения и распознавания плоскопечатных изображений, следовательно, он нуждается в специальной рельефной наглядности. Однако, применение рельефной наглядности требует определенной готовности незрячего ее воспринимать, т.е. состояние компенсаторных функций должно позволять ему воспринимать рельефную информацию, а это определенный уровень готовности анализаторов, восприятия, мышления, памяти и др. психических процессов. В противном случае, такая наглядность не информативна для незрячего, она не активизирует субъекта, его активность по-прежнему снижена, а, следовательно, не удовлетворяется потребность быть успешным в деятельности, возникает новая потребность во включении специального содержания коррекционной направленности. Т.е. обеспечивая потребность обучающегося в успешной деятельности, актуализируется субъективная потребность или запрос обучающегося в ином содержании.

Пример 2. Свойственная незрячему чрезмерная утомляемость приводит к фрустрации базовой потребности в психическом и физическом комфорте и, как следствие, определяет субъективно значимую потребность в движении, смене вида активности (необходимости размять энергичным движением утомленное статической нагрузкой тело), переключение на работу активизирующую другие сохранные анализаторы и т.д. И неудовлетворение этой потребности приведет с снижению активности субъекта, включенности в деятельность, повлияет на результат и т.д. Так, повышенная и ускоренная утомляемость обучающегося обуславливает потребность во включении в содержание урока своевременного отдыха или переключения на новую задачу, требующую активности иных процессов.

\section{Критерий 4. Предметность}

Содержание потребности должно обосновывать необходимость включения в образовательную среду специальных объектов, социокультурных условий, ресурсов и средств для успешного освоения содержания (материально-техническая составляющая развивающей среды).

В теории компенсации Л.И. Солнцева, Б.К. Тупоногов, и др., определяют использование специфических средств для осуществления обучения как обязательный компонент развивающей среды, в котором существует потребность у обучающихся с ОВ3. Например, потребность быть успешным в деятельности рождает необходимость компенсации недостатков получения визуальной информации лицами с нарушениями зрения. Так компенсация слабовидения обеспечивается, прежде всего, усилением визуального стимула в процессе восприятия необходимой для успешного осуществления деятельности информации, достаточный эффект достигается с помощью очковой коррекции, адаптации наглядности и интенсивности освещения. То есть, необходимость специальной наглядности и индивидуального освещения обуславливается потребностью обучающегося в деятельности и хорошем результате при наличии первичного дефекта - нарушения зрительных функций.

У незрячего, отсутствие зрительного восприятия визуальной информации в процессе деятельности, компенсируется включенностью и готовностью сохранных функций. Потребность в использовании сохранных анализаторов обеспечивается представлением визуальной информации в другом варианте, доступном для восприятия слепым. Следовательно, нужно обеспечить возможность овладения ребенком рельефной системой письма и чтения, что определяет в свою очередь, наличие специальных средств для письма и чтения, но главное нужно ввести это содержания в программы.

Естественная потребность человека в деятельности (по Э. Эриксону) определяет необходимость быть мобильным и ориентироваться в пространстве (так как любая деятельность предполагает движение и ориентировку в различных видах пространства), отсюда возникает нужда в тактильных дорожках и рельефных схемах, мнемосхемах, табличках и т.д. и в содержании, освоение которого формирует и совершенствует готовность обучающегося использовать специальные средства ориентации в различных видах пространства и деятельности.

Это особые архитектурные требования к организации образовательной среды, предназначенные для удовлетворения особых потребностей в условиях отдельных категорий обучающихся. И эти особые потребности являются и жизненными, и образовательными.

\section{Критерий 5. Полнота перечня}

Данный критерий предполагает, что учтены все потребности обучающегося, они соответствуют предъявляемым требованиям (критериям). Для определения полноты списка выделяемых особых образовательных потребностей обучающегося с ОВ3, необходимо провести экспертную оценку на соответствие требованиям (критериям). 


\section{Результаты}

Для составления списка образовательных потребностей обучающегося с ОВ3, нами был разработан способ или алгоритм выявления перечня особых образовательные потребностей обучающегося, соответствующего представленным научно обоснованным требованиям. Результат выработки ориентировочной основы действия (ООД) представлен в табл.2

\section{Зак^ючение}

Таким образом, предложенное содержание понятия «особые образовательные потребности» интегрирует психологические и дефектологические знания закономерностей и особенностей развития лиц с ограниченными возможностями здоровья. Оно может являться базой для решения различных практических задач образования обучающихся с ОВ3.

Разработанная ориентировочная основа действия выявления особых образовательных потребностей должна быть положена в основу выполнения основных профессиональных функций педагога и обеспечивать возможность, ставить цели, которые обеспечивают включение специфического коррекционного содержания в образование обучающихся, имеющих такие потребности, и которые уже сами по себе являются стимулирующим началом для достижения желаемого результата образования детей с ОВ3. Правильно определенные и учтенные особые образовательные потребности каждого обучающегося, позволят: во-первых, повысить их способности к обучению и познанию; во-вторых, увеличить продуктивность общения и педагогического взаимодействия с обучающимися данной категории; в-третьих, научиться эффективно руководить активностью обучающихся с ОВ3, организовывать их продуктивную работу и обеспечить субъективную позицию на уроках.

Известно, что современная система образования не может обеспечить решение задач эффективности инклюзивного образования без глубоко осознанной каждым педагогом необходимости, серьезно подходить к обеспечению качества образования всех обучающихся. Процесс определения и выявления особых образовательных потребностей достаточно трудоемкий, его не-

Таблица 2.

ООД выявления перечня особых образовательные потребностей обучающегося

Требования к результату (перечню потребностей):

1. Актуальность - актуальность для каждого конкретного субъекта в определенный момент времени, в определенной деятельности и т.д.

2. Достоверность научной обоснованностью диагностических выводов, результатов анализа данных и выделенных потребностей (обоснованных психофизиологической, психологической педагогической и др. науками).

\section{3. Субъективный характер потребности.}

Т.е. не включать потребности, которые не являются потребностями ребенка, а больше относятся к потребностям взрослых, учителей, директора школы.

Потребности должны быть обусловлены субъективными возможностями или недостатками обучающегося, определять содержание образования и сохранение субъективной активности при освоении определенного содержания

Это: потребность в адаптированном предметном содержании определяем возможностями ребенка, требования к личности педагога и психологопедагогической компетентности, родителей и других субъектов; требования к личности самого обучающегося; требование к методике.

\section{4. Предметность}

Содержание потребности должны быть предметным.

Содержание потребности должно обосновывать необходимость включения в образовательную среду специальных объектов, социокультурных условий, ресурсов и средств для успешного освоения содержания (материально-техническая составляющая развивающей среды).

делающие ее развивающей). Это: специально организованная образовательная среда - учебники, технические средства, форма организации работы и деятельности.

5. Полнота перечня - то есть учтены все потребности обучающегося.

\section{Способ (алгоритм) выявления 00П обучающегося:}

Определить цель выявления потребностей и временной промежуток их актуальности (т.е. какой промежуток времени выделенные потребности будут оставаться актуальными для обучающегося).

Осуществить анализ индивидуальной характеристики развития и функционирования обучающегося с ОВЗ (составленной по результатам комплексной диагностики медиков, психолога, педагогов, родителей) с фиксацией особенностей в индивидуальном состоянии основных психических процессов, состояний, свойств и психических образований.

Исходя из анализа особенностей и возможностей определить (спрогнозировать) возможные трудности в освоении содержания и описать психические состояния, при которых обучающийся испытывает необходимость в изменении содержания, осваиваемого на уроке (уроках).

Исходя из анализа особенностей и возможностей определить (спрогнозировать) возможные трудности в освоении содержания (урока или образовательной программы) и описать психические состояния, при которых обучающийся испытывает необходимость в специальных условиях среды и специальных ресурсах.

Провести экспертную оценку перечня потребностей. 
возможно решить без установки педагога на их решение и готовности к большим дополнительным усилиям. Однако масштаб этих задач, их судьбоносное значение для раскрытия потенциала и развития каждого ребенка с ОВ3 оправдывают любые усилия и энергию, затраченные на их достижение.

\section{ЛИТЕРАТУРА}

1. Богданова, Т.Г. Системный подход в анализе особых образовательных потребностей // Пермский педагогический журнал. - 2016. № 8. С. 28-31. URL: https://cyberleninka.ru/article/n/sistemnyy-podhod-v-analize-osobyh-obrazovatelnyh-potrebnostey/viewer (Дата обращения: 30.03.2021). - Текст: электронный.

2. Гончарова, Е.Л., Кукушкина 0.И. Ребенок с особыми образовательными потребностями // Альманах Института коррекционной педагогики. 2002. Альманах №5 URL: https://alldef.ru/ru/articles/almanah-5/rebenok-s-0sobymi-obrazovatelnymi-potrebnostjami (Дата обращения: 30.03.2021). - Текст: электронный.

3. Закон об образовании РФ (полный текст) [Электронный ресурс] : URL: - Режим доступа: zakonbase.ru. (дата обращения: 13.03.2021). - Текст : электронный.

4. Ильин Е.П. Мотивация и мотивы. — СПб.: Питер, 2002 - 512 с: ил. — (Серия «Мастера психологии»). ISBN 5-272-00028-5 - Текст: непосредственный.

5. Малофеев Н.Н. Концепция развития образования детей с ОВЗ: основные положения // Альманах Института коррекционной педагогики. 2019. Альманах №36. URL: https://alldef.ru/ru/articles/almanac-36/the-concept-of-development-of-education-of-children-with-disabilities (Дата обращения: 24.03.2021). Текст: электронный.

6. Приказ Министерства образования и науки РФ от 17 декабря 2010 г. № 1897 "0б утверждении федерального государственного образовательного стандарта основного общего образования" URL: http://www.garant.ru/products/ipo/prime/doc/55070507/\#ixzz3nrmfT400 (дата 0бращения: 13.01.2021). Режим доступа: по подписке. - Текст: электронный.

7. Приказ Минобрнауки России от 19.12.2014 N 1598 "0б утверждении федерального государственного образовательного стандарта начального общего образования обучающихся с ограниченными возможностями здоровья" (Зарегистрировано в Минюсте России 03.02.2015 N 35847)

URL: https://legalacts.ru/doc/prikaz-minobrnauki-rossii-ot-19122014-n-1598/ (дата обращения: 16.01.2021). - Режим доступа: по подписке. - Текст : электронный.

8. Примерные адаптированные образовательные программы для категорий обучающихся с ОВЗ в соответствии с ФГОС Н00 ОВЗ и ФГОС О у/0 (размещены на электронном ресурсе: $h$ ttp://fgosreestr.ru).

9. Приказ Министерства труда и социальной защиты РФ от 18 октября 2013 г. N 544н "0б утверждении профессионального стандарта "Педагог (педагогическая деятельность в сфере дошкольного, начального общего, основного общего, среднего общего образования) (воспитатель, учитель)" (с изменениями и дополнениями) [Электронный ресурc] : URL: http://ivo.garant.ru/\#/document/70535556/paragraph/1:0 (дата обращения: 29.03.2021). - Peжим доступа: по подписке. - Текст : электронный.

10. ФГОС для обучающихся с ограниченными возможностями здоровья [Электронный ресурc]: URL: http://fgos-ovz.herzen.spb.ru/ (дата обращения: 13.01.2021). - Режим доступа: по подписке. - Текст: электронный.

11. Эриксон Э. Идентичность: Юность и кризис: пер. с англ. / Общ. ред. и предисл. А.В. Толстых. — 2-е изд. — М.: Флинта, МПСИ, Прогресс, 2006.

(c) Кожанова Наталья Сергеевна (nskozhanova@rambler.ru). 